\title{
Instructional Design of Biochemistry Experiment Course Based on the Virtuality and Reality Combination in the Context of COVID-19 Epidemic
}

\author{
Di Jia ${ }^{1}$, Chunjing Zhang, ${ }^{1, *}$, Shuyan $\mathrm{Li}^{1}$, Zhenglin Zhao ${ }^{1}$ and Jing $\mathrm{Xu}^{1}$ \\ ${ }^{1}$ Department of Biochemistry, Qiqihar Medical University, Qiqihar, Heilongjiang 161006, China \\ "Corresponding author. Email: cjzhang2005@163.com
}

\begin{abstract}
Experiment teaching of biochemistry and molecular biology is indispensable to undergraduate medical education. In the context of COVID-19 epidemic, how to combine a virtual simulation platform with biochemistry laboratory experiments organically is a pressing problem that must be faced and solved. Based on the theories of "student-centered" and "cone of experience", department of biochemistry of Qiqihar Medical University took teaching mode of virtuality and reality combination as the research direction of exploration. Students learned the virtual simulation experiments, and improved their professional practical skills in traditional laboratory. Different from the traditional experiment teaching, the instructional design of virtuality and reality combination not only focused on improving students' acquisition of knowledge, but also paid attention to students' development of abilities and emotions. It could effectively improve the experiment teaching effect and strengthen the cultivation of innovative talents, which will greatly promote the reform of biochemistry experiment teaching in medical colleges and universities.
\end{abstract}

Keywords: Instructional design, biochemistry, experiment teaching, combination of virtuality and reality

\section{INTRODUCTION}

Biochemistry is an important basic compulsory course in medical colleges and universities. As an experimental science, experiment teaching of biochemistry and molecular biology is indispensable. It can help medical students understand the theoretical knowledge in textbooks, combine theory with practice, and strengthen the ability to apply knowledge. With the advent of the era of "Internet+", the deep integration of information technology and higher education has promoted the reform of educational concept, teaching mode, teaching method and teaching management system, bringing unprecedented opportunities to the development of education. Virtual simulation platform can simulate the environment of biochemistry experiments based on internet technology, and help the medical students to get real experience. The teaching model of combination of virtual simulation platform ("virtual") and traditional laboratory experiment ("real") has been gradually attached great importance to in universities at home and abroad.

At the beginning of 2020, COVID-19 was raging. In view of the continuing epidemic, the Ministry of Education issued a notice on January 27 to delay the start of the spring semester 2020 in order to control the further spread and cross-infection as soon as possible. In the context of COVID-19 epidemic, how to combine a virtual simulation platform with biochemistry laboratory experiment organically is a pressing problem that must be faced and solved. Since the spring semester of 2020, the department of biochemistry of Qiqihar Medical University has explored the combination of "virtual" and "real" in the experiment course. We have been working on how to attract the students' interests in the teaching content, and how to transform the emphasis from "teaching" to "learning" in biochemistry experiment instructional design. Virtual simulation platform could remedy the limitation of traditional laboratory experiment teaching, such as consuming time, particular places, and laboratory equipment. Students can conduct online learning, get rid of time and space constraints. Meanwhile, teachers can answer questions and monitor learning progress online. After the learning of virtual simulation platform, students can improve their professional practical skills in laboratory, consolidate the experience they have learned in the virtual simulation platform.

In conclusion, the combination of "virtual" and "real" is the future development and inevitable trend of experiment teaching of biochemistry and molecular biology. With the high-quality learning resource and online interactions between teachers and students, the blended online and offline teaching of biochemistry experiments could motivate students' autonomous learning interest, facilitate the information-based teaching, and promote the reform of experimental teaching. Furthermore, our practical application can also be used for the reference for experiment teaching reform at higher medical colleges and universities. 


\section{CURRENT SITUATION OF EXPERIMENT TEACHING OF VIRTUALITY AND REALITY COMBINATION}

According to the literature, in recent years, researchers focused on the importance of experiment teaching in medical teaching, existing problems and the construction of virtual platform of experiment teaching. In the file of "Ten-year Development Plan of Education Informatization (2011-2020)" issued by the Ministry of Education, it is proposed to vigorously promote the construction of digital campus in colleges and universities, build virtual simulation experiment platform, promote the reform of teaching content and teaching method, and promote the innovation of talent training mode[1]. In August of 2013, the Ministry of Education started the construction of national virtual simulation experiment teaching center, which was an important achievement of higher education quality engineering construction and an important part of education informatization [2]. $\mathrm{Li}$ et al. analyzed the importance of experiment teaching in medical biochemistry teaching, and put forward the development direction of experiment teaching reform, including promoting the in-depth integration of information technology and education [3]. Consequently, more and more online experiment courses based on the virtual simulation experiment platform begun to spring up in China.

At present, many colleges and universities at home and abroad are actively building medical virtual simulation experiment platform. The virtual simulation experiment is applied in biochemistry teaching, which could promote information technology and education teaching in-depth integration, and improve the teaching effect [4-5]. Virtual experiment environment is provided by virtual simulation platform based on internet technology, where learners could get real experience in the form of simulation. In the January of 2020, the Ministry of Education has issued a notice delaying the start of the spring semester in 2020 . According to the "Guiding Opinions on the Organization and Management of Online Teaching in General Institutions of Higher Learning" issued by the Ministry of Education, all schools deploy distance teaching programs. On the one hand, the online teaching programs of theoretical courses are relatively mature. On the other hand, the online teaching programs of experimental courses are still a problem that troubles all schools. Classes suspended but learning continues, Mengzhilu Experimental Platform offers free massive online experimental courses for medical students (http://www.yxsypt.com).

In traditional experimental teaching of biology, there are some disadvantages such as high cost, long time and slow updating. Nevertheless, in virtual experiment teaching, students and teachers can break through the limitation of distance and time. Different from traditional experimental teaching of biochemistry, virtual experiment teaching is free from experimental site, time, teaching funds and other conditions, and has the characteristics of intuitiveness, openness and safety. Students can actively choose study resources, control their learning process, and present their own idea more freely on web. It can effectively improve the experiment teaching effect and strengthen the cultivation of innovative talents, which will greatly promote the reform of molecular biology experimental teaching in medical colleges and universities [6].

However, in the preliminary virtual teaching practice, teachers realized that traditional experiment teaching is still the most important method of experimental teaching, which is more conducive to the cultivation of students' practical ability [7-8]. Only by adopting the experiment teaching mode combining virtual simulation with practical operation and complementing each other's advantages, can the experiment teaching quality be improved and the training objectives of undergraduates be met [9-11].

To sum up, the application research of combination of "reality" and "reality" in biochemistry and molecular biology is still in the preliminary stage. Therefore, we take the "combination of virtual and real, and supplement the real with virtual" as the research direction of exploration.

\section{THEORETICAL FOUNDATION OF INSTRUCTIONAL DESIGN OF VIRTUALITY AND REALITY COMBINATION}

\subsection{Theory of "student-centered"}

The concept of "student-centered" first appeared in the western countries at the end of the nineteenth century and the beginning of the twentieth. The western psychologist Rogers put forward humanistic theory[12], emphasizing the "people-centered" education, setting up the "student-centered" education concept, emphasizing the respect and trust of students, and giving play to the main role of students. And the American educator John Dewey put forward the pragmatic concept of education, advocating to transform traditional education form, and liberating child nature [13]. The Swiss psychologist Piaget put forward the constructivism theory, advocated to construct knowledge system according to students' cognitive structure, and paid attention to students' initiative in learning and the spirit of exploration [14]. The common point of these theories is that they all emphasize "student-centered", pay attention to students' interests and needs, give play to students' learning autonomy and innovation, and oppose the traditional education theory that focuses on knowledge transfer.

In the great industrial age of the 19th century, universities were organized as "mass production talents", forming a "standardized pipeline" of silo-like arrangement and combination. In this form of organization, teachers' teaching in the classroom was the basic element that constitutes a "silo". The universities naturally formed a "teacher-centered" organization mode and naturally extended to the "classroom-centered" and "textbook 
centered"[15]. In 1995, Robert B. Barr and John. Tagg indicated that a new paradigm of undergraduate teaching named as "learning paradigm", which initiated a paradigm revolution in American higher education [16]. Guided and inspired by this theory, a large number of universities around the world have carried out "student-centered" education and teaching reform, and jointly promoted the transformation from the traditional talent cultivation mode to the new talent cultivation mode.

With big data, the internet, as well as the application and market driving of artificial intelligence and other emerging technologies, students' personalized learning experience is more prominent, new explorations and experiments in the form of "adaptive" organization for student development emerge, and maintenance innovation and disruptive innovation thrive. About the theoretical basis, from the teaching of students as teachers in terms of the different roles of "student-centered, teacher-led" new model of biochemistry experiment teaching.

The biochemistry experiment teaching of combination of "reality" and "reality" takes "student-centered" as the key point of instructional design. It is the organic integration of virtual simulation platform and traditional laboratory, which realizes the combination of online and traditional classroom training, and provides online learning resources and guidance. And our ultimate goal is to help the students get the best learning effect.

\subsection{Dell's cone of experience}

In 1928, Weber put forward the theory of visual pedagogy in his book "The Value of Images in Education", indicating the importance of visual teaching [17]. Weber believed that visual sense played an important role in education and teaching. The use of language reduces students' interest in learning and makes it difficult for learners to understand the learning content. However, visual media vividly and intuitively presents the target knowledge, helps students understand the learning content, and has a significant effect in the learning process. Weber's way of thinking from the concrete to the abstract of visual media is real world $\rightarrow$ simulated reality $\rightarrow$ pictorial reality $\rightarrow$ graphic symbol $\rightarrow$ word symbol.

Based on this theory of visual pedagogy, American scholar Dale, put forward the famous "cone of experience" theory in his book theory of audio-visual teaching method in 1949. "Cone of experience" is the core of audio-visual teaching theory and a theoretical model of experience classification [18]. From the bottom to the top, "cone of experience" includes experience of doing, experience of observing, experience of abstracting, accords with the law of human cognition development. The theory holds that education should start from the concrete experience at the bottom of the tower and gradually transition to the abstract experience at the top.

Based on the "cone of experience", teachers should choose appropriate teaching media to present teaching content according to students' needs and cognitive abilities, and judge the status of selected media and whether students can understand it. The correct choice of media systematically combines the learners' direct and indirect experience, and helps students understand abstract concepts. In the biochemistry experiment teaching, some molecular biology concepts and methods are the abstractions of the top of the tower, such as plasmid extraction and reverse transcription. It is difficult for students to understand abstract concepts directly from direct and indirect experience. Teachers can use the teaching resources in the virtual experiment platform to help students understand.

\section{INSTRUCTIONAL DESIGN OF BIOCHEMISTRY EXPERIMENT COURSE BASED ON VIRTUAL AND REALITY COMBINATION}

Instructional design was a process, according to the level and requirements of educating objects, on the basis of settling down the reasonable starting and ending point of education, to reorganize and transform the content, to arrange instructional elements systematically and ordinary, then to form the instructional plan. In the biochemistry experiment teaching, we adopt the teaching mode of virtuality and reality combination. The biochemistry experiment course includes 1 designing experiment ("determination of salivary amylase activity") and 2 comprehensive experiments ("isolation and identification of $\gamma$ globulin" and "isolation and identification of plasmids"). And students are from 2019 undergraduate class of Qiqihar Medical University, majoring in general practice medicine, pharmacy, psychiatry, and nursing.

\subsection{Mode of virtuality and reality combination}

Combination of "virtual" and "real" is an organic combination of virtual simulation platform and laboratory practice. The virtual simulation platform adopted was the Mengzhilu virtual simulation experiment platform, which provides virtual biochemistry experiment environment for medical undergraduates and enables learners to get real experience in the form of simulation. QQ groups were established, teachers could release learning materials and videos in QQ groups. The organization of "virtual" experiment teaching is in the pattern of "Mengzhilu virtual simulation platform + QQ group". The biochemistry online experiments were carried out in the virtual environment to achieve teaching objectives and teaching effects. And the off-line experiments will be carried out when students return to school.

And the instructional design of our biochemistry experiment teaching takes "student-centered" as the key point. Compared with the traditional experiment teaching, the educating manner of virtuality and reality combination experiment teaching has changed significantly. Teachers transformed from the educating organizers of traditional 
education to the supporters of meeting various learning requirements. Students did not only rely on the instructions by educators but also learned and practiced by themselves autonomously. The ultimate goal is to help the students explore knowledge and information actively, and get the best learning effect.

\subsection{Teaching procedures}

In the situation of COVID-19, teachers in the department of biochemistry incorporated the students into different QQ groups, to facilitate the release of learning videos and materials, and to promote the communication between teachers and students. As shown in Figure 1, it spreads the steps of the teaching process, and explains the instructional events. Take the experiment of "isolation and identification of $\gamma$ globulin" as an example. The asynchronous method was adopted in teaching and learning, so as not to compel students to march forward synchronously in their study. It took 2 weeks for students to learn the knowledge in videos and materials, and finish the virtual experiment. And students will continue to practice the real experiments in lab when they return to school.

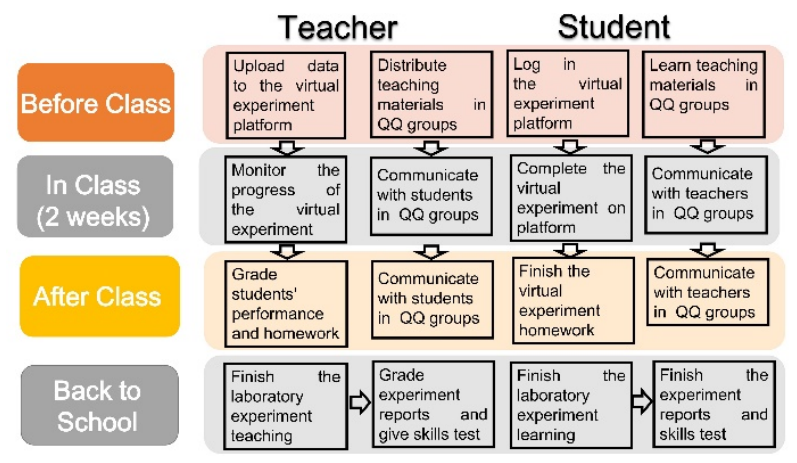

Figure 1. The steps of the teaching procedures of virtuality and reality combination

\subsubsection{Before class}

Before class, teachers uploaded student data to the virtual simulation experiment platform. At the same time, the teaching videos and materials were distributed in the QQ groups and exercises were prepared. The video contents included the experimental operation steps and principles, and the platform login and operation process were demonstrated.

\subsubsection{In class}

Based on the theory of "cone of experience", teachers used the teaching videos and the 3D virtual simulation experiments to help students understand the abstract principle. Students learned the teaching materials by themselves, logged on the virtual simulation experiment platform for virtual experiment operation, and completed the platform test questions and homework. During the 2 weeks, teachers can $\log$ on to the virtual simulation experiment platform to monitor students' learning progress and answer questions in the QQ group.

\subsubsection{After class}

At the end of the virtual experiment, students submitted the homework and finished quiz in QQ group. And teachers will grade students' virtual platform operation, homework and performance during the asynchronous teaching. Communication between teachers and students in QQ group, is helpful for students to study independently and think independently.

\subsubsection{Back to school}

When students return to school, laboratory experiment courses will be finished in the fall term of 2020. At the end of the virtual experiment and laboratory experiment courses, students will complete the experiment report, and teachers will grade students' skills tests in lab and experiment report.

\subsubsection{Ideological and political education}

In the instructional design of biochemistry experiment teaching, the ideological and political elements and teaching content were combined organically. For example, when teachers explained that globulin is produced by immune cells, which can improve human immunity and prevent virus infection, students were reminded to keep daily exercise and improve their immunity during the epidemic. In addition, the students were inspired to think about how to use the existing knowledge to purify serum globulin in the laboratory environment, to serve the clinical requires, since serum purification of globulin is the main source of clinical medication. Different from the traditional teaching mode, which only focuses on improving students' intelligence, the instructional design of virtuality and reality combination not only focuses on improving students' intelligence, but also pays attention to students' emotion.

\subsection{Teaching evaluation}

The total credit hours of the three experiments were 24 credit hours in traditional experiment teaching. Nevertheless, the experiment teaching of virtuality and reality combination, includes 6 weeks of asynchronous teaching on virtual platform, and 12 credit hours of synchronous teaching in lab. This course final grade will be 100 points, consists of students' virtual operation (50\%), laboratory skill operation test (30\%), experimental report 
and students' performance (20\%). The experimental test scores of students will be calculated, as the teaching effect is evaluated. In addition, a questionnaire survey will be conducted on students, which includes two aspects: the students' evaluation of teachers' teaching effect and self-practice ability.

\section{CONCLUSION}

In the context of COVID-19 epidemic, the department of biochemistry of Qiqihar Medical University has explored the combination of "virtual" and "real" in the experiment course. In this instructional design, students learned the virtual simulation experiments, and improved their professional practice skills in a traditional laboratory. Different from the traditional experiment teaching, the instructional design of virtuality and reality combination not only focused on improving students' acquisition of knowledge, but also paid attention to students' development of abilities and emotions. It could effectively improve the experiment teaching effect and strengthen the cultivation of innovative talents, which will greatly promote the reform of molecular biology experimental teaching in medical colleges and universities. With the deep integration of information technology and higher education, the virtuality and reality combination is the future development and inevitable trend of experiment teaching of biochemistry.

\section{ACKNOWLEDGMENT}

This work was supported by special project of 2020 teaching research program of Qiqihar Medical University (JGZX20200102).

\section{REFERENCES}

[1] Wang Jian. Promoting vocational education reform and innovation with educational informationization-interpretation of the ten-year development plan for educational informatization (2011-2020). Jiangsu Education Research, 2013(27):78-79. (In Chinese)

DOI:https://doi.org/10.13696/j.cnki.jer1673-9094.2013. 27.007

[2] The Ministry of Education of the People's Republic of China (MOE). Notice on the construction of national Virtual Simulation Experiment Teaching Center.

[EB/OL]. (2013-08-13)

http://www.Moe.gov.cn/s78/A08/A08_gggs/A08_sjhj/2

01308/t20130821_156121.html. (In Chinese)
[3] Li Zhengke, Sui Linlin, Xu Yuefei, Kong Ying. Exploration and practice of experiment teaching reform of biochemistry [J]. Management Observer, 2019(19):139-140. (In Chinese) DOI:https://doi.org/10.3969/j.issn.1674-2877.2019.19.0 57

[4]Scott Cooper. The use of MERLOT in biochemistry and molecular biology education [J]. Biochemistry and Molecular Biology Education, 2005, 33(5): 323-324. DOI: https://doi.org/10.1002/bmb.2005.49403305323

[5] Zeng Jing. Research on the reform of molecular biology experiment teaching based on virtual simulation platform [J]. Science and Education Guide (Previous ten-day), 2019(10):142-143. (In Chinese) DOI:https://doi.org/10.16400/j.cnki.kjdks.2019.10.068

[6] Guan Songlei. The application of virtual simulation experimental platform in experimental teaching $[\mathrm{J}]$. Journal of Changchun Institute of Education, 2018, 34(11):45-48. (In Chinese) DOI:https://doi.org/10.3969/j.issn.1671-6531.2018.11.0 12

[7]Zhang Hui, Yu Ting, Wang Guangli. Application of virtual Simulation technology in experimental teaching of Molecular biology [J]. Journal of Yi Chun College, 2018.40(9):115-118. (In Chinese)

DOI:https://doi.org/10.3969/j.issn.1671-380X.2018.09. 028.

[8]Chao Naixia, Zhou Qingniao, Wang Feng, Wu Yaosheng, Lan Xiuwan. Virtual experiment promotes the practice of biochemistry experiment teaching reform [J]. Basic Medical Education, 2018, 20(11):1017-1019. (In Chinese)

DOI:https://doi.org/10.13754/j.issn2095-1450.2018.11. 28

[9]Wang Hongmin, Sun Yanfei, Zhang Huaqiang, Wang Huilin, Dai Mengping. Exploration of college curriculum teaching based on students' ability cultivation [J]. China Modern Educational Equipment, 2020(01):116-119. (In Chinese)

DOI:https://doi.org/10.13492/j.cnki.cmee.2020.01.040

[10]Zhang Lijuan, Gu Tongnan, Yan Wen. Research on biochemistry experiment teaching mode based on "Internet + Education" [J]. Experimental Technology and Management, 2019, 36(09):181-183. (In Chinese) DOI: https://doi.org/10.16791/j.cnki.sjg.2019.09.046

[11] Xu Songyao, Hu Duanping, Xue Xin, Deng Feng, Jiang Lili, Li Jing, Ye Shumei. The experiment and 
application of biochemical virtual simulation experiment teaching project [J]. Basic Medical Education, 2019, 21(09):743-744. (In Chinese) DOI:https://doi.org/10.13754/j.issn2095-1450.2019.09. 24

[12] Brian Thorne. Spokesman of humanistic Psychology School-Rogers [M]. Shanghai: Xuelin Press, 2007:15.

[13] Wang Tian. On Dewey's thought of vocational education [J]. Education 2019, (27):48-49. (In Chinese) DOI:https://doi.org/10.3969/j.issn.1674-9510.2019.27.0 23.

[14] He Jianbo, Wang Zhen. Interpretation of contemporary Western constructivism teaching concept [J]. Higher Agricultural Education, 2013(05):79-82. (In Chinese)

DOI:https://doi.org/10.13839/j.cnki.hae.2013.05.020
[15] Zhao Juming, Gao Xiaohui. On the Reform of undergraduate Teaching based on "students-centered" [J]. China Higher Education Research, 2017, (8):36-40. (In Chinese) DOI:https://doi.org/10.16298/j.cnki.1004-3667.2017.08. 08

[16] Robert B. Barr, John Tagg. From Teaching to Learning-A New Paradigm for Undergraduate Education [J]. Taylor \& Francis Group, 2012, 27(6). DOI: https://doi.org/10.1080/00091383.1995.10544672

[17] Duan Aifeng. Research on the Development of Educational Technology thought in the United States. Ph.D. Thesis, Hebei University, 2016. (In Chinese)

[18] Yang Songyao, Zhan Shichang. Literature review on "The Cone of Experience" in China [J]. Software Guide (Educational Technology), 2018, 17(06):90-93. (In Chinese)

DOI:https://doi.org/10.16735/j.cnki.jet.2018.06.038 